\title{
A IMPORTÂNCIA DA RESIDÊNCIA PEDAGÓGICA NA FORMAÇÃO DOCENTE DOS LICENCIANDOS DO CURSO DE EDUCAÇÃO DO CAMPO DE ARRAIAS-TO: DIFICULDADES, AVANÇOS E PERSPECTIVAS
}

The importance of Pedagogical Residence in the teaching formation of licensors of the education course of the field of Arraias-TO: difficulties, advances and perspectives

La importancia de la Residencia Pedagógica en la formación docente de los

licenciantes del curso de educación del Campo de Arraias-TO: dificultades, avances y perspectivas

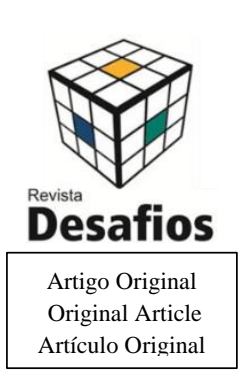

\section{Aparecida de Jesus Soares Pereira $^{* 1}$, Waldir Pereira da Silva ${ }^{1}$}

${ }^{1}$ Laboratório de Educação Musical, Curso de Licenciatura em Educação do Campo, Universidade Federal do Tocantins-UFT, Arraias -TO, Brasil.

*Correspondência: Curso de Licenciatura em Educação do Campo, Universidade Federal do Tocantins - UFT, Campus Professor Dr. Sérgio Jacintho Leonor, Av. Juraíldes de Sena e Abreu, Setor Buritizinho/ sala 10 - Bloco Bala, Arraias - Tocantins, Brasil.CEP:77.330-000.e-mails: cida.soares@uft.edu.br

\section{Artigo recebido em 03/04/2020 aprovado em 09/04/2020 publicado em 16/04/2020.}

\section{INTRODUÇÃO}

O Programa Residência Pedagógica - PRP é uma ação implementada pela Coordenação de Aperfeiçoamento de Pessoal de Nível Superior CAPES para atender aos objetivos da Política Nacional de Formação de Professores da Educação Básica do Ministério da Educação (CAPES, 2020).

No âmbito do Curso de Licenciatura em Educação do Campo Códigos de linguagens Artes Visuais e Música do Campus de Arraias - TO, o referido programa tem como objetivo a formação docente nas/para as escolas campesinas, sendo que a área de atuação do residente deve ter estreita relação com a área de formação acadêmica e profissional para associar teoria e prática.

A percepção que se tem quanto ao desenvolvimento do PRP e sua contribuição é que além da inserção do ensino de música nas escolas do campo, pôde também contribuir para a formação de professores que atuam ministrando os conteúdos Artes Visuais e Música. Entende-se que foi um trabalho colaborativo envolvendo e integrando a Instituição de Ensino Superior e as Escolas de Educação Básica, ficando estabelecido o tripé: Universidade, Estágio e Escolas.

\section{METODOLOGIAS E MATERIAIS}

As atividades do RP iniciaram em agosto de 2018 tendo 2 núcleos do Curso de Educação do Campo, um deles o "Subprojeto Educação Musical nas Escolas do Campo". A metodologia teve suas atividades como ponto de partida centrado no processo de ensino e aprendizagem dos alunos, colocando-os como sujeitos, respeitando suas potencialidades e investindo em suas habilidades, proporcionando aos mesmos a capacidade de investigação e de "aprender a aprender". Teve-se também como meta o desenvolvimento de ações práticas que vieram contribuir para a aplicação eficaz do ensino de música nas escolas, em cumprimento da Lei 11.769/2008 que versa sobre a obrigatoriedade do ensino de música nas escolas de educação básica (BRASIL, 2008). Quanto 
à atuação do residente nas escolas de Educação

Básica fez-se necessário compreender e aplicar as atribuições contidas na Base Nacional Comum Curricular destinadas ao ensino que propõe a criticidade, respeito às diferenças, à ética, tão importantes e necessários para o exercício da cidadania. Assim destaca-se a Arte no Ensino Fundamental que, segundo a BNCC (2017, p.191), “a Arte propicia a troca entre culturas e favorece o reconhecimento de semelhanças e diferenças entre elas". A proposta para as Artes é que haja uma articulação entre as áreas artísticas, a saber: Artes Visuais, Dança, Música e Teatro, constituindo a especificidade da construção do conhecimento em Arte na escola. O objetivo é trabalhar as dimensões da criação, crítica, estesia (ligada à sensibilidade e percepção dos sujeitos em relação ao próprio corpo, ao espaço, tempo, som, ação, imagens) e a expressividade. As atividades acadêmicas estiveram condicionadas ao princípio da ação-reflexão-ação, buscando proporcionar uma formação de qualidade no momento de refletir a profissão.

Os conteúdos e ações que foram desenvolvidos durante a residência na escola-campo tiveram em suas unidades temáticas objetos de conhecimento de cada área artística, especificamente das Artes Visuais e da Música, com uma carga horária total de 440 horas de efetiva atividade, ficando assim distribuídas: $1^{\mathrm{a}}$ etapa de planejamento e estudos, $2^{\mathrm{a}}$ etapa de ambientação do residente na escola-campo (totalizando até aqui 60 horas de atividades), $3^{\text {a }}$ etapa de imersão do residente na escola-campo, com um total de 320 horas direcionadas ao planejamento de aulas (60 horas), regência de classe (135 horas) e projetos de intervenção (125 horas), $4^{\mathrm{a}}$ etapa de elaboração do relatório final do residente com 20 horas incluindo avaliação e socialização das atividades com mais 40 horas. Foram organizados dois seminários com o intuito de socializar os resultados obtidos entre os núcleos do RP, com a participação dos residentes, comunidade escolar e acadêmica, apresentações de trabalhos científicos e artísticos, mesas redondas, palestras etc., resultados das ações advindas dos trabalhos realizados durante a regência e projetos de intervenção no período de Residência Pedagógica.

\section{RESULTADOS E DISCUSSÃO}

O Programa Residência Pedagógica procurou dar sentido e significado no âmbito tanto da sensibilidade subjetiva quanto das interações sociais, como resultado de saberes e valores diversos estabelecidos no domínio de cada cultura dentro do que preconiza a BNCC. Com isso, amplia-se a produção dos conhecimentos artísticos tanto dos residentes como dos alunos das escolas nessas áreas artísticas, possibilitando-os vivenciar estas práticas, interrelacioná-las à sua diversidade cultural e social, desenvolver seus próprios saberes colocando-os de forma ativa em seu convívio social.

A convivência do contexto escolar vai muito além de conhecer a rotina, os procedimentos obrigatórios, as normas e o ambiente. Nela, é possível perceber a dificuldade das instituições e de alguns professores na articulação dos conteúdos a serem trabalhados na disciplina, com os propósitos estabelecidos pelos documentos oficiais, as fragilidades operantes da necessidade de atuação em diferentes áreas, a formação superficial que recebem os professores e os livros didáticos que não desempenham sua devida relevância como suporte na tarefa do ensino das linguagens artísticas, especificamente quando não encontramos professores habilitados na área de formação em Artes, como é o caso da especificidade em música. Nesse sentido, cabe ressaltar a importância de entender a dinâmica escolar, a qual permite conhecer previamente a estrutura, instrumentos e recursos que a escola oferece, favorecendo a realização das aulas, a visão de ensino 
que a escola tem, um melhor planejamento, resultando em uma imersão mais aprofundada.

Pode-se perceber que em algumas escolas há poucos materiais didático-pedagógicos básicos ou quase nenhum para a ministração das aulas, e em se tratando da música muitos deles tiveram que ser reconstituídos e custeados pelos residentes e professores, e também muitos foram construídos com materiais recicláveis não duráveis. No caso das Artes Visuais muitos materiais como tintas foram improvisadas, pois todo material era necessário para as aulas. Em suma, tornou-se um desafio maior para o residente articular as aulas com poucos recursos que a escola disponibilizava.

Apesar das dificuldades o Programa Residência Pedagógica veio acrescentar tanto para a escola, quanto para o residente que teve a oportunidade de aprimorar suas práticas pedagógicas e contribuir para um ensino mais consistente do componente curricular em tela.

Outra dificuldade encontrada na realização das atividades do RP se deu também devido as especificidades do curso que tem um calendário diferenciado, atividades em regime de alternância com alunos de comunidades que abrangem outras regiões. Devido as distâncias das escolas selecionadas pela SEDUC dificultou a realização das atividades nas referidas escolas, e também para os residentes, pois tiveram que alojar nas escolas para realizarem as atividades.

Com o desenvolvimento do Programa Residência Pedagógica percebeu-se que a sua contribuição diante dos desafios apontados é que além da inserção do ensino de música nas escolas do campo, também o Programa contribuiu para a formação continuada de professores que atuam ministrando aulas de Artes.

\section{CONCLUSÃO}

O Programa Residência Pedagógica se apresentou como um instrumento eficaz na formação de professores e inserção do ensino de Artes Visuais e Música nas escolas do campo, contribuindo para o aperfeiçoamento da formação acadêmica. Esteve em consonância com o Estágio Curricular Supervisionado buscando articular teoria e prática possibilitando ao acadêmico ter mais oportunidades de vivenciar os conhecimentos adquiridos na academia e aplicá-los nas escolas. Entende-se que foi um trabalho colaborativo envolvendo e integrando a Universidade e as escolas de Educação Básica, fortificando o tripé: Universidade, Estágio e Escolas.

\section{AGRADECIMENTOS}

À Capes pelo incentivo financeiro. À instituição UFT por tornar possível a realização do programa de Residência Pedagógica. Ao Curso de Licenciatura em Educação do Campo Artes Visuais e Música de Arraias. Às Escolas parceiras.

Todos os autores declararam não haver qualquer potencial conflito de interesses referente a este artigo.

\section{REFERÊNCIAS}

BRASIL. Conselho Nacional de Educação. Lei de Diretrizes e Bases da Educação Nacional. Lei no. 9.394, de 20 de dezembro de 1996.

BRASIL. Presidência da República. Lei no 11.769 , de 18 de agosto de 2008. Altera a Lei n ${ }^{\circ} 9.394$, de 20 de dezembro de 1996, Lei de Diretrizes e Bases da Educação, para dispor sobre a obrigatoriedade do ensino da música na educação básica. Diário Oficial da União, Brasília, 2008.

BRASIL, Ministério da Educação. Base Nacional Comum Curricular: Educação é a Base. Brasília: DF, 2017.

COORDENAÇÃO DE APERFEIÇOAMENTO DE PESSOAL DE NÍVEL SUPERIOR - CAPES. Programa de Residência Pedagógica. Disponível em: https://www.capes.gov.br/educacaobasica/programa-residencia-pedagogica. Acesso em 2 de janeiro de 2020. 